\title{
Challenges and Treatment for Stroke Prophylaxis in Patients with Atrial Fibrillation in Mexico: A Review
}

\author{
Luis Alcocer ${ }^{1}$
}

Published online: 29 February 2016

(C) The Author(s) 2016. This article is published with open access at Springerlink.com

\begin{abstract}
Atrial fibrillation (AF) is associated with an increased risk of stroke. AF-related strokes cause greater disability and mortality than those in patients without AF, and are associated with a significant clinical and economic burden in Mexico. Antithrombotic therapy reduces stroke risk in patients with $\mathrm{AF}$ and is recommended for all patients except those classified as having a low stroke risk. However, its use is suboptimal all around the world; one study showed that only $4 \%$ of Mexican patients with AF who presented with ischemic stroke were in the therapeutic range for anticoagulation. Vitamin $\mathrm{K}$ antagonists (VKAs) such as warfarin or acenocoumarin have long been the only oral anticoagulants for stroke prevention in AF. Although effective, VKAs have disadvantages, including the need for regular coagulation monitoring and dose adjustment. Interactions with numerous common medications and foods contribute to the risk of serious bleeding and thrombotic events in VKA-treated patients. Thus novel oral anticoagulants (NOACs), more properly called direct oral anticoagulants (DOACs), such as dabigatran etexilate, rivaroxaban, apixaban, and edoxaban (not available in Mexico), have been developed. These offer the convenience of fixed-dose treatment without the need for monitoring, and have few drug or food interactions. Pivotal phase III trials have demonstrated that these agents are at least as effective as warfarin in preventing stroke and are associated with a reduced risk of intracranial hemorrhage. With apixaban approved in Mexico in April 2013,
\end{abstract}

Luis Alcocer

alcocerdb@gmail.com

1 Instituto Mexicano de Salud Cardiovascular, Tuxpan 16, 06760 Mexico, D.F., Mexico clinicians now have the choice of three novel DOACs as alternatives to warfarin. However, it is yet to be established which of these agents should be the first choice, and treatment decisions are likely to depend on the individual patient's characteristics.

\section{Key Points}

In Mexico, it is estimated that atrial fibrillation (AF) affects 426,025 people aged $>60$ years.

Cerebrovascular disease is the third leading cause of death in the country, with 31,999 deaths in 2013; about 5333 of those can be attributed to AFassociated stroke. The direct cost of managing AF would be the equivalent of between US\$0.7 and 1.89 billion a year. About 66,460 Mexicans with undetected AF could be receiving prevention therapy. If all people with AF were managed using oral anticoagulants, the number of preventable strokes would be approximately 1993, and this would provide potential cost offsets.

Direct oral anticoagulants (apixaban, dabigatran and rivaroxaban) have been widely used in Mexico since 2008 (since 2011, for stroke prophylaxis in patients with AF) and have demonstrated at least comparable effectiveness to that of vitamin $\mathrm{K}$ antagonists, with superior safety and simpler management. These agents may represent an opportunity for long-term management to be undertaken in anticoagulation clinics in the first level of health care, by trained primary care physicians, once the drug is prescribed by the specialist. 


\section{Introduction}

Atrial fibrillation (AF), the most common type of sustained cardiac arrhythmia, involves chaotic electrical activity in the atria that leads to rapid, irregular ventricular contraction [1]. In Mexico, there are no available direct statistics on the prevalence of AF, but the following calculations can be made based on data published in the Mexican General Census of Population and Housing 2010 [2] and data on AF prevalence and mortality worldwide. The prevalence of $\mathrm{AF}$ in the general population is estimated to be 1-2\% [3-5]. As the total population of Mexico in 2013 was 122,300,000 [2], this suggests that the prevalence of AF in Mexico is between $1,223,000$ and 2,446,000. This figure is very high, probably because of the age structure of the Mexican population, so a more believable figure is one adjusted for age; the prevalence of $\mathrm{AF}$ increases with age, and $\mathrm{AF}$ in older individuals is predominantly nonvalvular. An estimated $3.8 \%$ of individuals aged $>60$ years have AF [5]. In Mexico, there are 11,211,186 people aged >60 years; therefore, it can be estimated that 426,025 people in this age group will have AF. Similarly, the prevalence of AF among people aged $>80$ years has been estimated to be as high as $15 \%[3,5,6]$. Thus, with $1,662,432$ people in this age group in Mexico, as many as 249,365 could have AF. $\mathrm{AF}$ is associated with increased morbidity and mortality due to complications including heart failure, systemic embolism and stroke, and results in an impaired quality of life $[1,3]$. Patients with nonvalvular AF have a fivefold increase in the risk of stroke, and one in every five strokes is attributable to $\mathrm{AF}$ [3]. In addition to the higher incidence of stroke among patients with AF versus the general population, strokes associated with $\mathrm{AF}$ are often more severe and debilitating than other strokes, and are associated with higher rates of disability and mortality [7]. In Mexico in 2013, cerebrovascular disease was the third leading cause of death, with 31,999 deaths. It can be calculated that approximately 5333 of these deaths (one in six) were due to AF-associated stroke. This estimate is consistent with a study that found AF in $15.2 \%$ of the 7669 patients hospitalized for first stroke in 2005 at five hospitals in Mexico City [8]. In the PREMIER registry (Mexican First Record Cerebral Ischemia), which included 1376 patients, mechanisms of cerebral ischemia were classified as undetermined (41\%), cardioembolism (20\%), small vessel disease $(20 \%)$, large vessel disease $(8 \%)$ and various mechanisms (5\%); the frequency of $\mathrm{AF}$ among patients with stroke or transient ischemic attack (TIA) in this registry was $10 \%$ [9]. In a combined analysis of three Mexican records with a total of 3194 patients with stroke or TIA, the frequency of AF was $12.5 \%$ among patients with stroke and $8.1 \%$ in patients with TIA [10]. The direct cost of managing AF was calculated to be $0.9-2.4 \%$ of the total National Health Service (NHS) budget in the UK in 2000 [11]. In Mexico in 2014, the total health expenditure was US\$78.82 billion, so, assuming a similar proportion of the total budget, we can calculate that the direct cost of managing AF would be the equivalent of between US $\$ 0.7$ and 1.89 billion a year. On the other hand, in Mexico, 426,025 people aged $>60$ years will have AF. If we assume, conservatively, that about $24 \%$ have undetected $\mathrm{AF}$ and $35 \%$ of these will have irreversible contraindications for warfarin [12], then about 66,460 Mexicans with undetected AF could be receiving prevention therapy. If all of these people were managed using oral anticoagulants, the number of preventable strokes would be approximately 1993, and this would provide potential opportunity cost offsets (in averted lifetime costs from first-ever ischemic stroke events), taking into account that the risk of stroke in patients with AF can be significantly reduced with appropriate use of antithrombotic medications, which is recommended for all patients except those with the lowest risk [1]. This review aims to describe the available pharmacological options for the prevention of stroke in patients with $\mathrm{AF}$ in Mexico and the challenges associated with these treatments, with a focus on the newly available direct oral anticoagulants (DOACs).

\section{Anticoagulants in Stroke Prevention}

Oral antithrombotic agents, in particular anticoagulants, are effective in reducing the risk of stroke in patients with $\mathrm{AF}$ [3]. Anticoagulants inhibit blood clotting via one or more steps in the coagulation cascade, and include oral vitamin $\mathrm{K}$ antagonists (VKAs), direct thrombin inhibitors, direct factor Xa inhibitors, and parenteral agents [unfractionated and low-molecular-weight heparins (LMWHs), direct thrombin inhibitors, and the indirect factor Xa inhibitor fondaparinux]. Because primarily oral anticoagulants are used in stroke prevention in AF, this review will focus on these agents. VKAs have long been the mainstay of stroke prevention in AF. VKAs inhibit coagulation by inhibiting the recycling of vitamin $\mathrm{K}$ epoxide back to the active reduced form of vitamin $\mathrm{K}$ [13]. Treatment with VKAs has been shown to reduce the relative risk (RR) of stroke or systemic embolism compared with control or placebo by $64 \%$ [95\% confidence interval (CI) 49-74], with an absolute RR of $2.7 \%$ per year (number needed to treat, 37) for embolism in patients with no history of prior stroke, $8.4 \%$ per year (number needed to treat, 12) for patients with a history of prior stroke, and $26 \%$ (95\% CI 3-43\%; absolute RR $1.6 \%$ per year) for all-cause mortality [14]. Aspirin, an antiplatelet agent, has also been shown to reduce the risk of stroke in patients with AF. A $42 \%$ RR 
reduction was seen with aspirin $325 \mathrm{mg}$ /day versus placebo in the Stroke Prevention in AF (SPAF)-I study [15]. However, a meta-analysis of studies in which aspirin doses ranged from 50 to $1300 \mathrm{mg}$ /day showed only a nonsignificant $19 \%$ reduction in the incidence of first stroke versus placebo [14]. Furthermore, meta-analysis of studies directly comparing VKAs and aspirin showed VKAs to be significantly more effective (38\% RR reduction) [14]. Dual antiplatelet therapy with aspirin plus clopidogrel has also been evaluated for stroke prevention in AF. Atrial Fibrillation Clopidogrel Trial with Irbesartan for Prevention of Vascular Events (ACTIVE-W) found warfarin to be more effective ( $40 \%$ relative stroke risk reduction), and while Atrial Fibrillation Clopidogrel Trial with Irbesartan for Prevention of Vascular Events (ACTIVE-A) demonstrated that aspirin plus clopidogrel was significantly more effective than aspirin alone ( $28 \%$ RR reduction), dual antiplatelet therapy was associated with a significantly higher incidence of major bleeding events $[16,17]$. Historically, in Mexico the paradigm on the use of anticoagulants for the prevention of stroke in patients with AF was to determine "which patients require anticoagulation." However, recently this paradigm has changed to the current concept, or "Who are the real stroke low-risk patients, who do not require anticoagulants?" (given their low absolute risk for stroke). The 2012 European Guidelines for stroke prevention in $\mathrm{AF}$ recommend the use of anticoagulants in all patients except those classified as low risk (i.e., patients who are $<65$ years of age and have no other cardiovascular or concomitant disease), or without contraindications for the use of these drugs [18-20]. The choice of anticoagulation therapy should be based on individual patients' RRs of stroke/thromboembolism and bleeding and the net clinical benefit (the balance between ischemic stroke prevention and the potential risk of serial bleeding, in general $>1.5$-fold) [18]. The risk of stroke in patients with AF is not homogenous, and anticoagulants may not be warranted in patients who do not have certain risk factors. To identify low-risk patients, various thromboembolism/stroke risk assessment tools have been developed [21]. The most widely used are $\mathrm{CHADS}_{2}$ and $\mathrm{CHA}_{2} \mathrm{DS}_{2}$-VASc (Birmingham 2009 schema) [21, 22]. The $\mathrm{CHADS}_{2}$ score estimates patients' stroke risk based on the presence of five major risk factors (Table 1). However, it has only modest predictive value (c-statistic of 0.58 ) and classifies most patients as being 'moderate-risk' $[3,21]$. Thus, while the $\mathrm{CHADS}_{2}$ score is useful in the initial assessment of patients with $\mathrm{AF}$, use of a more detailed, risk factor-based tool, $\mathrm{CHA}_{2} \mathrm{DS}_{2}$-VASc, is recommended when determining which treatment (if any) should be prescribed [3]. In the $\mathrm{CHA}_{2} \mathrm{DS}_{2}$-VASc score, vascular disease, age 65-74 years, and female sex are incorporated into the original $\mathrm{CHADS}_{2}$ score (Table 1). An evaluation of $\mathrm{CHA}_{2} \mathrm{DS}_{2}$-VASc showed
Table 1 Calculation of $\mathrm{CHADS}_{2}$ and $\mathrm{CHA}_{2} \mathrm{DS}_{2}$-VASc risk scores $[21,22]$

\begin{tabular}{lll}
\hline Risk factor & $\begin{array}{l}\mathrm{CHADS}_{2} \\
\text { score [22] }\end{array}$ & $\begin{array}{l}\mathrm{CHA}_{2} \mathrm{DS}_{2}-\mathrm{VASc} \\
\text { score [21] }\end{array}$ \\
\hline Cardiac failure & 1 & 1 \\
Hypertension & 1 & 1 \\
Age $\geq 75$ years & 1 & 2 \\
Diabetes & 1 & 1 \\
Stroke or TIA & 2 & 2 \\
Vascular disease & - & 1 \\
Age 65-74 years & - & 1 \\
Sex category (female) & - & 1 \\
Maximum score & 6 & $9^{\mathrm{a}}$ \\
\hline
\end{tabular}

TIA transient ischemic attack

${ }^{a}$ Maximum score is 9, as the two age categories are mutually exclusive

that although the predictive value was only slightly higher than that for $\mathrm{CHADS}_{2}$ (c-statistic of 0.606), patients were less likely to be incorrectly classified as low risk [21].

All antithrombotic agents are associated with an increased risk of bleeding events, including intracranial hemorrhage (ICH) and other forms of major bleeding. In some patients, the risk of bleeding associated with antithrombotic therapy may outweigh the potential benefit of treatment, despite these patients having an elevated risk of ischemic stroke [23]. Bleeding risk in patients for whom anticoagulant therapy is being considered may be assessed using indices such as the HAS-BLED score [24]; however, these tend to be less well validated than stroke risk scales [23]. Risk factors for bleeding include hypertension, renal and/or hepatic impairment, prior stroke, age $>65$ years, low bodyweight, unstable or high international normalized ratio (INR) values, concomitant medications (e.g., antiplatelet agents, NSAIDs), and alcohol abuse [24]. International practice guidelines recommend that patients with at least one additional stroke risk factor (this includes males with a $\mathrm{CHA}_{2} \mathrm{DS}_{2}$-VASc score of 1 and a score of 2 or higher for everyone else) receive oral anticoagulants, either VKA with a target INR range of 2.0-3.0 or DOACs, unless contraindicated [18-20]. The recommendations and the use of the $\mathrm{CHADS}_{2}$ score and other risk factors in determining the appropriate stroke prophylaxis for patients with $\mathrm{AF}$ are summarized in the clinical flowchart shown in Fig. 1. Recommendations regarding the use of DOACs will be discussed later in this article.

\subsection{Vitamin K Antagonists}

The most commonly used VKAs are the coumarins; the most prominent member of this class is warfarin. Warfarin 
Fig. 1 Clinical flowchart for the use of oral anticoagulation for stroke prevention in $\mathrm{AF}$ (Modified from the 2012 ESC Guideline for the management of atrial fibrillation [3], and 2014 Focused Update of the Canadian Cardiovascular Society Guidelines for the Management of Atrial Fibrillation [78]). $A F$ atrial fibrillation, bid twice daily, $D O A C$ direct oral anticoagulant, GI gastrointestinal, INR international normalized ratio, TIA transient ischemic attack, $V K A$ vitamin $\mathrm{K}$ antagonist

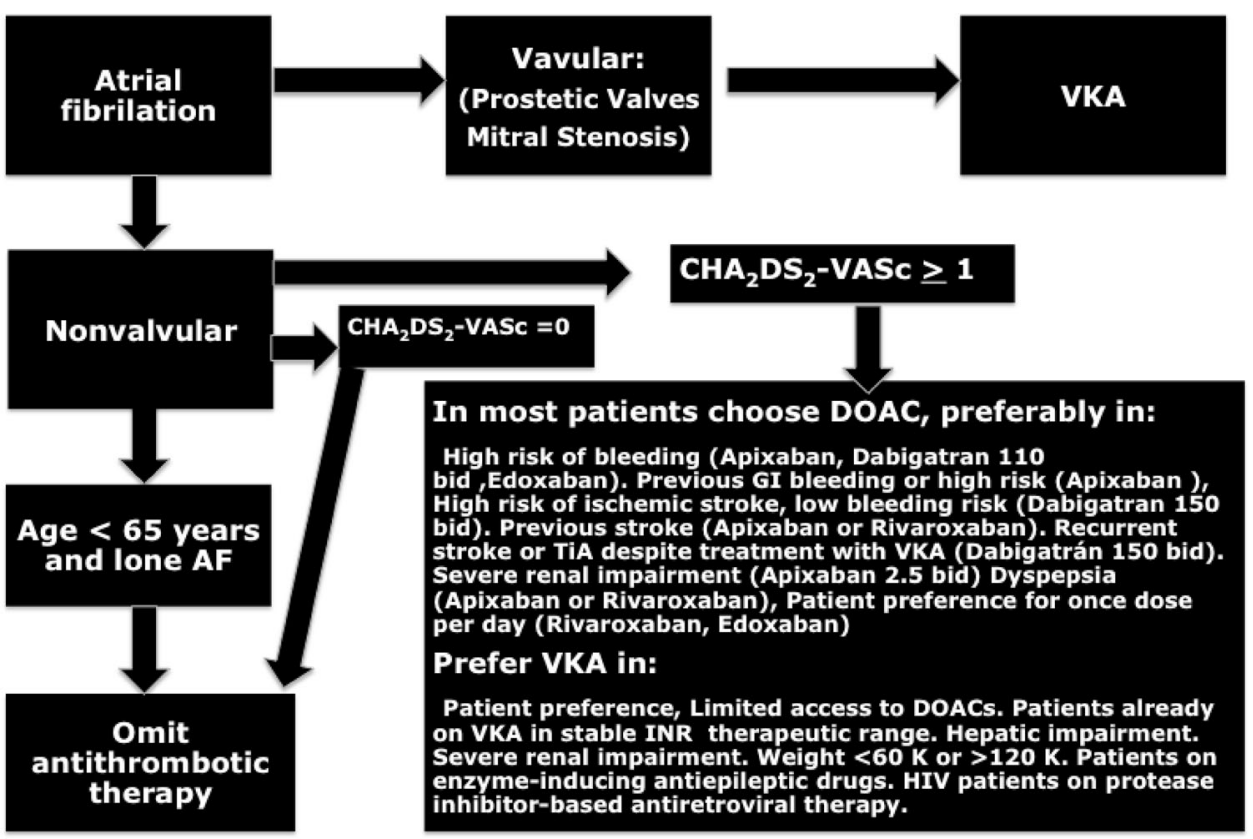

inhibits the synthesis of the calcium-dependent clotting factors II, VII, IX, and X, as well as the regulatory factors protein $\mathrm{C}$, protein $\mathrm{S}$, and protein $\mathrm{Z}[13,25]$. Warfarin is currently the most commonly used anticoagulant to prevent stroke in patients with AF worldwide; however, acenocoumarin is widely used in Mexico, most other Latin American countries, and Spain. VKAs are recommended by evidence-based guidelines [3, 20, 26] as they have been shown to be highly effective for reducing the risk of stroke [27]. However, they have numerous disadvantages. Because of its mechanism of action, warfarin has a slow onset and offset of action [13]. Activated coagulation factors produced before warfarin intake will continue to function until degraded [13]. Furthermore, warfarin has a long half-life (20-60 h), which leads to its slow offset of action $[13,28]$. In cases where reversal of anticoagulation is required, the effects of warfarin can be reversed with vitamin $\mathrm{K}$; however, the onset of action of vitamin $K$ is $6 \mathrm{~h}$ and its maximal effect is $18-20 \mathrm{~h}$. When rapid reversal is needed, for example, in patients with major bleeding or those requiring urgent surgery, prothrombin complex concentrate or fresh frozen plasma can be used [13]. Another disadvantage of warfarin is its narrow therapeutic range (target INR range usually 2.0-3.0 in patients with AF), and that regular monitoring of the INR and dose adjustment are required to ensure an adequate yet safe dose is taken [13]. An INR below the therapeutic target indicates that the dose of warfarin is insufficient to protect against thromboembolic events, whereas INRs exceeding the therapeutic range increase the risk of major bleeding events [13]. Warfarinassociated bleeding is among the most common causes of drug-related morbidity and mortality and accounts for
$33 \%$ of reported adverse drug event-related hospitalizations, $71 \%$ resulting from excessive doses [29]. While the majority of patients enrolled in clinical trials of warfarin remain in the INR range of 2.0-3.0, INR control is often suboptimal in the 'real world' clinical practice setting, with the average time spent in therapeutic range (TTR) ranging from $56 \%$ in retrospective studies to $65 \%$ in randomized controlled trials [30, 31]. Warfarin interacts with a large number of commonly used medications and certain foods (particularly leafy greens that contain large amounts of vitamin K) [32]. Often, these interactions lead to INR values being outside the appropriate therapeutic range [32]. Caution with concomitant medication use (including herbal medicines) and diet is therefore necessary in patients receiving warfarin.

\subsection{Direct Oral Anticoagulant (DOACs)}

In an effort to address the shortcomings of VKAs and to improve patient outcomes, DOACs have been developed that offer fixed-dose administration, have reduced potential for drug and food interactions, and do not require routine coagulation monitoring. These include the direct thrombin inhibitor dabigatran etexilate and the direct factor $\mathrm{Xa}$ inhibitors rivaroxaban, apixaban, and edoxaban, which are marketed (edoxaban not marketed in Mexico), and agents in late-stage clinical development, such as betrixaban (Table 2). These DOACs have been studied, and in some cases, they have received regulatory approval, in indications for which warfarin is used: stroke prevention in AF, primary prevention of venous thromboembolism (VTE) following orthopedic surgery, treatment and secondary 
Table 2 Direct oral anticoagulants in development for the prevention of stroke in atrial fibrillation worldwide

\begin{tabular}{|c|c|c|c|c|c|}
\hline Drug & Manufacturer & $\begin{array}{l}\text { Mechanism of } \\
\text { action }\end{array}$ & Phase of development & $\begin{array}{l}\text { Frequency of } \\
\text { administration }\end{array}$ & Clinical trial(s) \\
\hline $\begin{array}{l}\text { Dabigatran } \\
\text { etexilate }\end{array}$ & Boehringer Ingelheim & $\begin{array}{l}\text { Thrombin } \\
\text { inhibitor }\end{array}$ & Marketed & Twice daily & RE-LY \\
\hline Apixaban & $\begin{array}{l}\text { Pfizer/Bristol-Myers } \\
\text { Squibb }\end{array}$ & $\begin{array}{r}\text { Factor Xa } \\
\text { inhibitor }\end{array}$ & Marketed & Twice daily & $\begin{array}{l}\text { ARISTOTLE, } \\
\text { AVERROES }\end{array}$ \\
\hline Rivaroxaban & Bayer/Janssen & $\begin{array}{r}\text { Factor Xa } \\
\text { inhibitor }\end{array}$ & Marketed & Once daily & ROCKET-AF \\
\hline Edoxaban & Daiichi Sankyo & $\begin{array}{r}\text { Factor Xa } \\
\text { inhibitor }\end{array}$ & $\begin{array}{l}\text { Marketed (not in } \\
\text { Mexico) }\end{array}$ & Once daily & ENGAGE AF-TIMI 48 \\
\hline
\end{tabular}

prevention of VTE, and in acute coronary syndrome (ACS). The three DOACs that have been approved in Mexico for stroke prevention in AF, dabigatran etexilate, rivaroxaban, and apixaban, will be discussed further. Advantages of the DOACs include their predictable pharmacological effects, which allow fixed-dose administration without the need for routine coagulation monitoring and dose adjustment [33]. These agents also have a rapid onset of effect and relatively short half-lives [28]. Furthermore, they have reduced potential for interactions with drugs and foods compared with warfarin [33]. However, these agents also have certain drawbacks, such as the lack of standard coagulation monitoring techniques; although coagulation monitoring will not usually be necessary, it may be desirable in some cases, for example, in determining whether a serious bleeding event is associated with excessive anticoagulation or when considering thrombolysis for patients with acute thrombotic stroke [34].

Another relative disadvantage of the novel oral anticoagulants is the potential need and current access to agents that neutralize the action of DOACs. The short half-lives of the novel anticoagulants should mean antidotes are not necessary in many cases, although they may be desirable in situations such as severe bleeding episodes or where emergency surgery is required. It should be noted that fondaparinux, low-molecular-weight heparin (LMWH) have been used successfully for many years despite the lack of antidotes for these agents [34].

Three molecules may provide an effective and safe way of reversing the anticoagulant effects of DOACs:

1. Idarucizumab (Praxbind ${ }^{\circledR}$ ), a fragment of an antibody (Fab), which is a specific antidote to the oral direct thrombin inhibitor dabigatran, has been recently approved in the USA by the Food and Drug Administration (FDA) and in Europe by the European Medicines Agency (EMA). Interim results of 90 patients of the planned 300 from the RE-VERSal Effects of Idarucizumab on Active Dabigatran Trial (RE-VERSE AD) study [35] suggests that $5 \mathrm{~g}$ of intravenous idarucizumab is safe and effective in completely reversing the anticoagulant effect of dabigatran within minutes in patients with AF who had serious bleeding (51 patients) or required urgent procedure (39 patients).

2. Andexanet alfa (r-Antidote, PRT064445; Portola Pharmaceuticals) is a recombinant, modified truncated form of enzymatically inactive factor Xa molecule, which binds and reverses the anticoagulant action of both the direct factor Xa inhibitors (e.g., rivaroxaban, apixaban, and edoxaban) and the indirect Factor $\mathrm{Xa}$ inhibitors (e.g., fondaparinux) [36]. Andexanet in older healthy participants in the trials Andexanet Alfa a Novel Antidote to the Anticoagulant Effects of fXA Inhibitors-Apixaban Trial (ANNEXA-A) (48 participants randomly assigned to receive apixaban and 17 placebo) and Andexanet Alfa a Novel Antidote to the Anticoagulant Effects of fXA Inhibitors-Rivaroxaban Trial (ANNEXA-R) (53 patients randomly assigned to receive rivaroxaban and 27 placebo) [37] reversed the induced changes in anti-factor Xa activity and thrombin generation, and also reduced unbound factor $\mathrm{Xa}$ inhibitor concentrations in apixaban- and rivaroxabantreated patients rapidly after an intravenous bolus, sustaining that effect through a continuous infusion, without evidence of clinical toxic effects or clinical thrombosis.

3. Aripazine (PER-977, ciraparantag; Perosphere Inc.) is an intravenously administered synthetic small molecule ( $500 \mathrm{Da})$ for use as a broad-spectrum reversal agent for anticoagulants that reverses oral dabigatran, apixaban, and rivaroxaban, and subcutaneous fondaparinux, unfractionated heparin (UFH) and LMWH in vivo. It received fast-track status by the US FDA in April 2015 as an investigational anticoagulant reversal agent [38].

A high level of adherence is also important with the DOACs, as each has a short-half life and their anticoagulant effects will wear off after missing two or three doses, 
whereas warfarin will maintain its anticoagulant effects for considerably longer after the last dose [28]. Finally, all of the direct anticoagulants have some degree of renal elimination and their half lives are all increased in case of renal impairment [39], meaning there is potential for drug accumulation and hence increased bleeding risk in patients with renal dysfunction; in particular, the use of dabigatran etexilate requires that renal function is reviewed 2-3 times per year [18]; in contrast, elimination of warfarin is entirely hepatic [28].

\subsubsection{Dabigatran Etexilate}

Dabigatran etexilate (Pradaxa ${ }^{\circledR}$; Boehringer Ingelheim) is an orally absorbed prodrug of dabigatran, a thrombin inhibitor that has potent anticoagulant and antithrombotic activity. Dabigatran etexilate competitively inhibits both free and clot-bound thrombin, which is responsible for the conversion of fibrinogen into fibrin (dabigatran etexilate is rapidly converted by a serum esterase to dabigatran and has an absolute bioavailability of $6.5 \%$ ) [40]. Dabigatran etexilate has a serum half-life of $12-17 \mathrm{~h}$, and $80 \%$ of the administered dose is excreted renally [40]. Dabigatran etexilate is administered as a twice-daily oral dose that does not require titration or coagulation monitoring. It has been approved in 75 countries since 2008, including Mexico, and is indicated for primary prevention of VTE following major orthopedic surgery [41] and prevention of stroke and systemic embolism in patients with nonvalvular AF [42]. Dabigatran was approved by COFEPRIS, the Mexican drug regulatory agency, for the prevention of stroke and systemic embolism in patients with AF in June 2011 [43]. In Mexico, a 150-mg twice daily dosage is indicated for all patients, except those with a potential risk of major bleeding (e.g., those $\geq 75$ years old), a CHADS $_{2}$ score of $\geq 3$, and/or previous gastrointestinal bleeding, those receiving concomitant $\mathrm{P}$-gp inhibitors, or those with moderate renal impairment [creatinine clearance $\left(\mathrm{CL}_{\mathrm{CR}}\right)$ $30-50 \mathrm{~mL} / \mathrm{min}$ ], for whom the approved dose is $110 \mathrm{mg}$ twice daily [42]. Dabigatran etexilate is contraindicated in patients with severe renal impairment $\left(\mathrm{CL}_{\mathrm{CR}}<30 \mathrm{~mL} /\right.$ $\mathrm{min})$. Dabigatran etexilate has been recommended as an alternative to warfarin for the prevention of stroke and thrombosis in patients with nonvalvular AF in updated treatment guidelines $[19,20]$.

Clinical Trials: Regulatory approval of dabigatran etexilate for stroke prevention in AF is based on the findings of the Randomized Evaluation of Long-term anticoagulation therapY (RE-LY) trial (ClinicalTrials.gov record: NCT00262600) [44]. RE-LY was a non-inferiority trial comparing the long-term efficacy and safety of dabigatran etexilate with warfarin for the prevention of stroke and systemic embolism in patients with AF (Table 3) [44]. Dabigatran etexilate dosage was blinded, but warfarin treatment was open-label. The primary efficacy endpoint was the incidence of stroke or systemic embolism. Dabigatran etexilate was non-inferior to warfarin in preventing the primary endpoint in patients with $\mathrm{AF}$, with comparable or lower rates of major bleeding depending on the dose [45]. Dabigatran etexilate $110 \mathrm{mg}$ twice daily met the predefined non-inferiority criteria versus warfarin, while dabigatran etexilate $150 \mathrm{mg}$ twice daily was superior to warfarin (RR 0.66; $95 \%$ CI 0.53-0.829). After a subsequent analysis of RE-LY looked at the association between dabigatran and clinical/silent as well as other ischemic myocardial events, there is debate as to whether the risk of

Table 3 Efficacy and safety studies of the direct oral anticoagulants in nonvalvular atrial fibrillation

\begin{tabular}{lllll}
\hline & Dabigatran RE-LY & Rivaroxaban ROCKET-AF & Apixaban ARISTOTLE & Edoxaban ENGAGE AF \\
\hline$N$ :Randomized & 18,113 & 14,264 & 18,201 & 21,105 \\
Mean age (years old) & 72 & 73 & 70 & 72 \\
Female (\%) & 27 & 40 & 35 & 38 \\
Paroxysmal AF (\%) & 32 & 18 & 15 & 25 \\
VKA naive (\%) & 50 & 38 & 43 & 41 \\
Aspirin use (\%) & 40 & 36 & 31 & 29 \\
Median TTR (\%) & 66 & 58 & 66 & 68 \\
Mean CHADS Score & 2.1 & 3.5 & 2.1 & 2.8 \\
Efficacy: RR (95\% CI) & $0.66(0.53-0.82)$ & $0.80(0.75-1.3)$ & $0.80(0.67-0.95)$ & $0.88(0.75-1.02)$ \\
Safety: RR (95\% CI) & $0.93(0.81-1.7)$ & $1.03(0.96-1.11)$ & Superior & $0.80(0.71-0.90)$ \\
Efficacy & $150 \mathrm{mg}$ : superior & Non-inferior & & Non-inferior \\
Safety & $110 \mathrm{mg}$ : non-inferior & & Superior & Superior \\
\hline
\end{tabular}

$A F$ atrial fibrillation, $C I$ confidence interval, $R R$ relative risk, $T T R$ time spent in therapeutic range, $V K A$ vitamin $\mathrm{K}$ antagonist 
heart attack is higher with dabigatran compared to warfarin [46], When you look at the totality of benefits with dabigatran-the reduction in hemorrhagic stroke [47], ischemic stroke [48], and bleeding [49] vs the increased number of MI-there is clearly a net clinical benefit in favor of dabigatran over warfarin.

\subsubsection{Rivaroxaban}

Rivaroxaban (Xarelto ${ }^{\circledR}$; Bayer, Janssen) is a direct inhibitor of factor Xa. Factor $\mathrm{Xa}$ is involved in the intrinsic and extrinsic coagulation pathways and is responsible for the conversion of prothrombin to thrombin $[50,51]$. Consistent with the observation that coagulation progresses in an amplified manner, one molecule of factor Xa catalyzes the formation of approximately 1000 molecules of thrombin [52, 53]. Inhibition of factor $\mathrm{Xa}$ can effectively prevent both platelet-rich arterial thrombi and fibrin-rich venous thrombi [54]. Rivaroxaban has an oral bioavailability of 63-79 \% and a half-life of $7-13 \mathrm{~h}$; only $36 \%$ is excreted in urine as unchanged drug. In addition, $\sim$ two-thirds is excreted as inactive metabolites and feces, although there are hepatic drug interactions with strong P-gp and CYP3A4 inhibitors and inducers, with the remainder being eliminated via the liver [28]. Rivaroxaban is indicated for the prevention of VTE in adults undergoing hip and knee replacement surgery, for the short- and long-term treatment of patients with deep vein thrombosis and pulmonary embolism, and for stroke prevention in patients with nonvalvular AF [50]. It was approved by COFEPRIS in Mexico for the prevention of thromboembolic events in patients with nonvalvular AF in March 2012, and in December 2012 for the secondary prevention of ACS. The recommended dose of rivaroxaban for stroke prevention in AF is $20 \mathrm{mg}$ once daily, which should be administered with food [50]. In patients with moderate renal impairment $\left(\mathrm{CL}_{\mathrm{CR}}<50-30 \mathrm{~mL} / \mathrm{min}\right)$ the recommended dose of rivaroxaban is $15 \mathrm{mg}$ once daily. The drug may be used with caution in patients with severe renal impairment $\left(\mathrm{CL}_{\mathrm{CR}}\right.$ $15-29 \mathrm{~mL} / \mathrm{min}$ ), and is contraindicated in those with endstage renal disease (ESRD) $\left[\mathrm{CL}_{\mathrm{CR}}<15 \mathrm{~mL} / \mathrm{min}\right.$ ).

Clinical Trials: Evidence for the efficacy of rivaroxaban in stroke prevention in AF comes from the Rivaroxaban Once Daily Oral Direct Factor Xa Inhibitor Compared with Vitamin K Antagonism for Prevention of Stroke and Embolism Trial in Atrial Fibrillation (ROCKET-AF). ROCKET-AF was a phase III, randomized, multicenter, double-blind, active-controlled trial investigating the efficacy of rivaroxaban versus warfarin in 14,264 patients with nonvalvular AF who were at an increased risk of stroke (ClinicalTrials.gov record: NCT00403767) [55]. Patients were randomized to rivaroxaban $20 \mathrm{mg} /$ day (or $15 \mathrm{mg} /$ day in patients with moderate renal impairment at screening) or to dose-adjusted warfarin titrated to an INR of 2.5 [55].
The primary efficacy endpoint was the incidence of stroke (hemorrhagic or ischemic) or systemic embolism. The primary safety endpoint was the incidence of major and clinically relevant non-major bleeding events. In the intentto-treat analysis, rivaroxaban was non-inferior to warfarin, with a stroke/systemic embolism rate of $2.1 \%$ per year in the rivaroxaban arm versus $2.4 \%$ per year in warfarintreated patients [hazard ratio (HR) 0.88; $95 \%$ CI 0.75-1.03; $p<0.001$ for non-inferiority] [55]. The rates of the primary safety endpoint were similar in the rivaroxaban and warfarin arms (14.9 vs. $14.5 \%$; HR 1.03; $95 \% \mathrm{CI}$ $0.96-1.11 ; p=0.44)$; however, the incidences of ICH and fatal bleeding were significantly reduced with rivaroxaban ( 0.5 vs. $0.7 \%, p=0.02$, and 0.2 vs. $0.5 \%, p=0.003$, respectively). The efficacy and safety findings of ROCKET-AF were consistent across pre-specified patient subgroups, including patients with renal impairment, and across TTR quartiles for the warfarin arm, in the intent-totreat analysis and not in the per-protocol analysis; the ontreatment sub group analysis, which was pre-specified, demonstrated superiority [55] (Table 3).

\subsubsection{Apixaban}

Like rivaroxaban, apixaban [Eliquis ${ }^{\circledR}$, Bristol Myers Squibb and Pfizer (International), and Elicuis ${ }^{\circledR}$, Pfizer (Mexico)] is an oral pyrazole-based direct factor Xa inhibitor. Apixaban has an oral bioavailability of $66 \%$ and a half-life of $8-15 \mathrm{~h}$ [28]. Elimination of apixaban occurs via multiple routes. Of the administered apixaban dose in humans, approximately $25 \%$ was recovered as metabolites, with the majority recovered in feces. Renal excretion of apixaban accounts for approximately $27 \%$ of total clearance. Additional contributions from biliary and direct intestinal excretion were observed in clinical and nonclinical studies, respectively. Apixaban was approved for the prevention of stroke and systemic embolism in patients with nonvalvular AF in Mexico in 2013, in the European Union (EU) in November 2012, and in the USA in December 2012 [56, 57]; it is also indicated in the EU for the prevention of VTE in adult patients who have undergone elective hip or knee replacement surgery [58]. In Mexico it was approved also for prevention of VTE in adults undergoing hip and knee replacement surgery, and for the short- and long-term treatment of patients with deep vein thrombosis and pulmonary embolism. The recommended dose of apixaban for patients with $\mathrm{AF}$ is $5 \mathrm{mg}$ twice daily, although a reduced dose ( $2.5 \mathrm{mg}$ twice daily) is recommended for patients with two or more of the following characteristics: age $\geq 80$ years, bodyweight $\leq 60 \mathrm{~kg}$, and serum creatinine $\geq 1.5 \mathrm{mg} / \mathrm{dL}$.

No dose adjustment is recommended for patients with renal impairment alone, including those with ESRD maintained on hemodialysis, except nonvalvular AF 
patients who meet the criteria for dosage adjustment defined in the previous paragraph [58].

Clinical Trials: Two phase III trials have investigated the efficacy and tolerability of apixaban for stroke prevention in patients with AF (Table 3) [59, 60]. The multinational Apixaban for Reduction In STroke and Other ThromboemboLic Events in Atrial Fibrillation (ARISTOTLE) trial compared apixaban with warfarin (ClinicalTrials.gov record: NCT00412984) [59]. The primary efficacy endpoint was the incidence of stroke (hemorrhagic or ischemic) or systemic embolism, and the primary safety endpoint was major bleeding. ARISTOTLE demonstrated that apixaban was more effective than warfarin in reducing stroke, with the primary endpoint occurring at a rate of $1.27 \%$ per year versus $1.51 \%$ per year in the warfarin group; the between-group difference met predefined superiority criteria (Table 3) [59]. The incidence of major bleeding events and the rate of ICH and death were also significantly lower with apixaban versus warfarin (both $p<0.001)$. Secondary analysis of the ARISTOTLE results showed no evidence of differential benefits of apixaban versus warfarin in different stroke or bleeding risk categories [61] and that apixaban demonstrated consistent effects in patients with a previous stroke or TIA and those without. The Apixaban Versus Acetylsalicylic Acid to Prevent Stroke in Atrial Fibrillation in Patients Who Have Failed or Are Unsuitable for Vitamin K Antagonist Treatment (AVERROES) trial was designed to determine whether apixaban was superior to aspirin for preventing the composite outcome of stroke or systemic embolism in patients with $\mathrm{AF}$ and at least one additional risk factor for whom VKA therapy was considered unsuitable (ClinicalTrials.gov record: NCT00496769) [62]. Patients were randomized to apixaban or aspirin, and the primary efficacy endpoint was the incidence of stroke or systemic embolism. AVERROES was intended to follow patients for a treatment period of up to 36 months; however, the trial was ended early after an interim analysis by the Data and Safety Monitoring Committee determined that apixaban demonstrated overwhelmingly superior efficacy compared with aspirin. The primary endpoint occurred at rates of 1.6 and $3.7 \%$ per year in patients receiving apixaban and aspirin, respectively; the between-group difference met predefined superiority criteria (Table 3). Rates of major bleeding, the primary safety endpoint, were similar in the apixaban and aspirin groups, and consistency in treatment effects was seen across patient subgroups. As seen in the other novel anticoagulant studies, patients with prior stroke or TIA had higher incidences of stroke or systemic embolism than those without, regardless of which treatment arm they had been assigned to [62]. However, the incidence was significantly reduced with apixaban compared with aspirin in both subgroups (major bleeding also occurred more frequently in patients with a previous stroke or TIA than those without, but no significant difference was seen between apixaban and aspirin in either subgroup) (Table 3).

\subsubsection{Edoxaban}

Edoxaban is a new DOAC, not available in Mexico [63], whose mechanism of action involves direct and reversible inhibition of factor Xa. It has a $62 \%$ bioavailability with a half-life (terminal) of 10-14 h. It is metabolized minimally by hydrolysis conjugation and CYP3A4-mediated oxidation. It is excreted $50 \%$ unchanged in urine; because of its high renal clearance, blood levels of edoxaban are higher in patients with impaired renal function. Systemic exposure to edoxaban was $>70 \%$ higher among patients with a $\mathrm{CL}_{\mathrm{CR}}$ of $\leq 50 \mathrm{~mL} / \mathrm{min}$ than among those with a $\mathrm{CL}_{\mathrm{CR}}$ of $>80 \mathrm{~mL} /$ min.

Clinical Trials: Edoxaban versus warfarin in patients with atrial fibrillation trial (ENGAGE AF-TIMI 48) [64] is a randomized, double-blind trial comparing two once-daily regimens of edoxaban with warfarin in 21,105 patients with $\mathrm{AF}$ and a $\mathrm{CHADS}_{2}$ score of 2, with a median follow-up to 2.8 years. Each edoxaban regimen was tested for non inferiority to warfarin. The principal safety endpoint was major bleeding. Both once-daily regimens of edoxaban were non-inferior to warfarin with respect to the prevention of stroke or systemic embolism and were associated with significantly lower rates of bleeding and death from cardiovascular causes. Comparing both edoxaban doses, the high dose has greater efficacy in the prevention of ischemic events, particularly ischemic stroke, at the cost of more bleeding, including intracranial hemorrhage, however hemorrhagic strokes and CV mortality were both significantly lower on both edoxaban regimens than on warfarin. There is a balance between the efficacy and safety of the two doses; no differences between the two doses in overall mortality and cardiovascular mortality were observed. The primary endpoint (stroke or systemic embolism) occurred after a median follow-up of 2.8 years at a significantly lower annual rate with edoxaban than with warfarin (1.18 vs. $1.50 \%$ ). Edoxaban use was also associated with significantly reduced annual rates of major bleeding ( 2.75 vs. $3.43 \%)$, intracranial bleeding ( 0.39 vs. $0.85 \%$ ), and cardiovascular death (2.74 vs. $3.17 \%)$. Among patients with a $\mathrm{CL}_{\mathrm{CR}}$ of $>95 \mathrm{~mL} / \mathrm{min}$, the rate of ischemic stroke was significantly higher with edoxaban $(0.9 \%)$ than with warfarin $(0.4 \%)$ [65] (Table 3).

\subsection{Indirect Comparisons of the DOACs}

With the approval of apixaban in Mexico in April 2013 by the Mexican Drug Agency (COFEPRIS [Comisión Federal 
para la Protección contra Riesgos Sanitarios]), and with dabigatran and rivaroxaban already available, clinicians in Mexico have the same choice of three novel oral anticoagulants for stroke prevention in AF as those in the USA and Europe. It is therefore important that certain questions are answered in the near future. The first question is whether the novel oral anticoagulants should replace warfarin. A recent meta-analysis of data from four DOACs, studied for the prevention of stroke or systemic embolic events in patients with AF not valvular, showed that oral direct anticoagulants had a favorable benefit-risk profile, with significant reductions in stroke, ICH, and mortality and severe bleeding similar to warfarin, but increased gastrointestinal bleeding [66]. The most important advantage with the use of any of the three novel oral anticoagulants is that they are associated with reduced rates of ICH compared with warfarin, as ICH is arguably the most feared complication of oral anticoagulant therapy [67]. The main limitation of the novel oral anticoagulants is that none has been followed for a long time, whereas VKAs have been in use for $>50$ years and there is a large amount of clinical data on their long-term use.

Another key question that arises is which of the three novel anticoagulants should be the first choice. Several pooled analyses have not been able to provide a consensus on this [68-71], and there have been no head-to-head clinical trials of these agents in patients with AF; however, differences in their pharmacokinetic and pharmacodynamic properties and data from clinical trials may help determine which treatment is best suited to particular patients [72] (Fig. 1).

There is currently a lack of specific data on the effects of the DOACs in Mexican or Hispanic patients in phase III trials; therefore, treatment decisions must be based on effects in the overall patient population. Nevertheless, it should be noted that the Mexican population was indeed included in both of the pivotal apixaban trials and in studies of dabigatran and rivaroxaban; while a specific sub-analysis of these global population studies in Mexican patients cannot be conducted as they were not powered for subpopulation analyses, these direct anticoagulants were effective in these patients. Although dabigatran, rivaroxaban, and apixaban all showed reductions in ICH versus warfarin in phase III studies, dabigatran $150 \mathrm{mg}$ twice daily was the only drug that reduced the risk of cerebral infarction over warfarin. Dabigatran and apixaban were the only ones to show a significant reduction in stroke/systemic embolism, and only apixaban significantly reduced mortality and major bleeding $[45,55,59]$. Both dabigatran and rivaroxaban were associated with significantly increased gastrointestinal bleeding versus warfarin, but apixaban was not. Apixaban and rivaroxaban are less dependent on renal elimination than dabigatran, and appear to be less likely to be associated with gastrointestinal adverse events [45, 55, 59]. The 2014 American Heart Association/American Stroke Association (AHA/ASA) "Guidelines for the Prevention of Stroke in Patients With Stroke and Transient Ischemic Attack" recommend VKA therapy (class I; level of evidence A), apixaban (class I; level of evidence A), and dabigatran (class I; level of evidence B) for the prevention of recurrent stroke in patients with nonvalvular $\mathrm{AF}$, whether paroxysmal or permanent [73]. Updated guidelines from the American College of Chest Physicians recommend dabigatran $150 \mathrm{mg}$ twice daily rather than VKAs (grade 2B), but do not make recommendations regarding the use of apixaban or rivaroxaban as they were not approved at the time of drafting the guidelines [20]. The most recent European Society of Cardiology (ESC) guidelines recommend the use of these DOACs (a direct thrombin inhibitor or a factor Xa inhibitor) when VKAs cannot be used because of difficulties in keeping within therapeutic anticoagulation, an inability to attend or undertake INR monitoring or the occurrence of adverse events with VKAs (class IB) [18]. When oral anticoagulants are recommended, either a direct thrombin inhibitor or a factor Xa inhibitor should be considered rather than a VKA, as in most patients with nonvalvular AF, based on their net clinical benefit (class IIa, level A) [18] (Fig. 1). The management of anticoagulated patients undergoing surgery is a common clinical problem; AF accounts for the largest percentage of this particular clinical situation. Surgical or other invasive procedures were required in a quarter of patients in RE-LY and a third of patients in ROCKET-AF and ARISTOTLE. Of the 4591 patients underwent at least 1 invasive procedure in the RE-LY trial, the perioperative thromboembolic risk was $1.2 \%$, based on a combined endpoint of stroke, cardiovascular death, and pulmonary embolism [74]. There were no differences in thromboembolic risk with dabigatran compared with warfarin or high- versus low-dose dabigatran. However, urgent surgery was associated with an increased risk of ischemic stroke or systemic embolism (warfarin 1.8 vs. $0.4 \%$; dabigatran $150 \mathrm{mg}$ twice daily 1.4 vs. $0.4 \%$; dabigatran $110 \mathrm{mg}$ twice daily 2.8 vs. $0.3 \%$ ). Of the 4692 ROCKET anticoagulant interruptions, $40 \%$ were for surgery or invasive procedures [65]. Thromboembolic risk during anticoagulant interruption was similar to that for rivaroxaban and warfarin $(0.3$ and $0.4 \%)$. During 9260 procedures performed on patients in the ARISTOTLE trial, perioperative thromboembolic risk was $0.57 \%$ for warfarin and $0.35 \%$ for apixaban [75]. Two of these trials showed that treatment absolutely must not combine LMWH/UFH/fondaparinux with NOACs. In Mexico, local guidelines regarding stroke prevention in $\mathrm{AF}$ are very basic. Two guidelines are available, one relating to the management of anticoagulants and the other the 
management of AF in primary care [76, 77]. These guidelines do not discuss the use of novel oral anticoagulants in patients with $\mathrm{AF}$ and are thus not suitable for the current clinical situation. Thus, we can assume that Mexican physicians will rely on their own clinical judgment and international guidelines to inform their prescribing decisions until local Mexican guidelines are updated.

\section{Conclusions}

Patients with AF generally have an increased risk of stroke. While warfarin is very effective at reducing stroke risk in these patients, it has several significant disadvantages, including the need for regular coagulation monitoring and dose adjustment and a large number of interactions with other medications and with certain foods. Several direct anticoagulants have recently become available that circumvent the issues seen with warfarin, and while there is not yet the wealth of data from clinical trials and the use of these agents in clinical practice that there is for warfarin, the data thus far for these agents in the prevention of stroke in $\mathrm{AF}$ have been promising. AF and its complications (such as stroke) are a growing problem in Mexico, which can be explained in particular by the increasing population aged over 65 years. Prevention of thromboembolic complications of AF using anticoagulants is a very effective and cost-effective strategy. The VKAs have been used successfully for many years and have been shown to significantly decrease stroke risk in patients with nonvalvular AF; however, their subsequent management is complex. Health services in the Mexican public sector are staggered, so that the first level medical health provider is one who should diagnose the presence of $\mathrm{AF}$ and refer the patient to the second or third level of provider for anticoagulant prescribing and management. Ideally, the long-term management of anticoagulants should be monitored in the first level of health care; however, the complexity of traditional anticoagulant management has made it necessary for their prescription and management to occur in specialized centers such as anticoagulation clinics. Such centers are complex and expensive to establish and maintain, and in Mexico, they are often overwhelmed by a huge demand. While popular belief is that the DOACs are very expensive, they in fact represent a niche opportunity for optimization of limited health resources, particularly for the prevention of stroke in AF. The DOACs have been broadly used in Mexico since 2008, and have demonstrated at least comparable effectiveness to that of VKAs, with superior safety and simpler management. These agents may represent an opportunity for long-term management to be undertaken by the primary care physician once the drug is prescribed by the specialist. The diagnosis of $\mathrm{AF}$, communicating the need for the lifetime use of anticoagulants to prevent stroke and other complications, and the proper handling of anticoagulants all require continuous medical education, directed not only to the specialist but also to the general practitioner.

Acknowledgments Medical writing assistance for the preparation of this manuscript was provided by Raewyn Poole, inScience Communications, Springer Healthcare, and Simone Boniface, inScience Communications, Springer Healthcare; this assistance was funded by Bristol-Myers Squibb and Pfizer (Mexico).

\section{Compliance with Ethical Standards}

Disclosure statement Dr. Alcocer received an unrestricted educational grant from Bristol-Myers Squibb and Pfizer in connection with the development of this manuscript. Dr. Alcocer has also received consulting fees for non-commercial advisory board activities and speaker fees and travel support (related to speaking engagements) from Pfizer (Mexico) and Bristol-Myers Squibb.

Open Access This article is distributed under the terms of the Creative Commons Attribution-NonCommercial 4.0 International License (http://creativecommons.org/licenses/by-nc/4.0/), which permits any noncommercial use, distribution, and reproduction in any medium, provided you give appropriate credit to the original author(s) and the source, provide a link to the Creative Commons license, and indicate if changes were made.

\section{References}

1. Lafuente-Lafuente C, Mahe I, Extramiana F. Management of atrial fibrillation. BMJ 5. 2009;339:b5216.

2. La Situación Demográfica en México 2013 [online]. http://www. conapo.gob.mx/en/CONAPO. Accessed 6 June 2015.

3. Camm AJ, Kirchhof P, Lip GY, et al. Guidelines for the management of atrial fibrillation: the Task Force for the Management of Atrial Fibrillation of the European Society of Cardiology (ESC). Eur Heart J. 2010;31(19):2369-429.

4. Stewart S, Hart CL, Hole DJ, et al. Population prevalence, incidence, and predictors of 14 atrial fibrillation in the Renfrew/ Paisley study. Heart. 2001;86(5):516-21.

5. Go AS, Hylek EM, Phillips KA, et al. Prevalence of diagnosed atrial fibrillation in adults: national implications for rhythm management and stroke prevention: the AnTicoagulation and Risk Factors in Atrial Fibrillation (ATRIA) Study. JAMA. 2001;285(18):2370-5.

6. Heeringa J, van der Kuip DA, Hofman A, et al. Prevalence, incidence and lifetime risk of atrial fibrillation: the Rotterdam study. Eur Heart J. 2006;27(8):949-53.

7. Jørgensen HS, Nakayama H, Reith J, et al. Acute stroke with atrial fibrillation. The 22 Copenhagen Stroke Study. Stroke. 1996;27(10):1765-9.

8. Cabrera-Rayo A, Martinez-Olazo O, Laguna-Hernández G, Iuarez Ocaña $\mathrm{R}$, Rosas-Barrientos $\mathrm{V}$, Loria-Castellanos $\mathrm{J}$, Medellin-García R, Ceron-Juárez R, Sanchez-Mata F, ÁlvarezTorrecilla L, Rumbo-Nava U. Epidemiologia de la enfermedad vascular cerebral en hospitales de la Ciudad de Mexico. Estudio multicentrico. Med Int Mex. 2008;24(2):98-27 (103).

9. Cantu-Brito C, Ruiz-Sandoval JL, Murillo-Bonilla LM, Chiquete E, Leon-Jimenez C, Arauz A, Villarreal-Careaga J, RangelGuerra R, Ramos-Moreno A, Barinagarrementería F, PREMIER investigators. Acute care and 30 on-year outcome of Mexican 
patients with first-ever acute ischemic stroke: the PREMIER 31 study. Rev Neurol. 2010;51:641-9.

10. Barinagarrementeria F. Prevencion de embolismo por FA. Gac Med Mex. 2011;147:248-56.

11. Stewart S, Murphy NF, Walker A, et al. Cost of an emerging epidemic: an economic 36 analysis of atrial fibrillation in the UK. Heart. 2004;90(3):286-92.

12. Sudlow M, Thomson R, Thwaites B, et al. Prevalence of atrial fibrillation and eligibility for anticoagulants in the community. Lancet. 1998;352(9135):1167-71.

13. Ansell J, Hirsh J, Hylek E, et al. Pharmacology and management of the vitamin $\mathrm{K}$ antagonists: American College of Chest Physicians Evidence-Based Clinical Practice Guidelines (8th Edition). Chest. 2008;133(6 Suppl):160S-98S.

14. Hart RG, Pearce LA, Aguilar MI. Meta-analysis: antithrombotic therapy to prevent stroke in patients who have nonvalvular atrial fibrillation. Ann Intern Med. 2007;146(12):857-67.

15. Stroke Prevention in Atrial Fibrillation Study. Final results. Circulation. 1991;84(2):527-47 (39).

16. Active Writing Group of the ACTIVE Investigators, Connolly S, Pogue J, et al. Clopidogrel plus aspirin versus oral anticoagulation for atrial fibrillation in the Atrial fibrillation Clopidogrel Trial with Irbesartan for prevention of Vascular Events (ACTIVE $52 \mathrm{~W}$ ): a randomised controlled trial. Lancet. 2006;367(9526):1903-12.

17. Connolly SJ, Pogue J, et al. Effect of clopidogrel added to aspirin in 54 patients with atrial fibrillation. $\mathrm{N}$ Engl $\mathrm{J}$ Med. 2009;360(20):2066-78.

18. Camm AJ, Lip GY, De Caterina R, ESC Committee for Practice Guidelines-CPG, Document Reviewers, et al. 2012 focused update of the ESC Guidelines for the management of atrial fibrillation: an update of the 2010 ESC Guidelines for the management of atrial fibrillation. Europace. 2012;14(10):1385-413.

19. January CT, Wann LS, Alpert JS, American College of Cardiology/American Heart Association Task Force on Practice Guidelines, et al. 2014 AHA/ACC/HRS guideline for the management of patients with atrial fibrillation: a report of the American College of Cardiology/American Heart Association Task Force on Practice Guidelines and the Heart Rhythm Society. J Am Coll Cardiol. 2014;64(21):e1-76.

20. You JJ, Singer DE, Howard PA, et al. Antithrombotic therapy for atrial fibrillation: Antithrombotic Therapy and Prevention of Thrombosis, 9th ed: American College of Chest Physicians Evidence-Based Clinical Practice Guidelines. Chest. 2012;141(2 Suppl):e531S-9 (75S).

21. Lip GY, Nieuwlaat R, Pisters R, et al. Refining clinical risk stratification for predicting stroke and thromboembolism in atrial fibrillation using a novel risk factor-based approach: the euro heart survey on atrial fibrillation. Chest. 2010;137(2):263-72.

22. Gage BF, Waterman AD, Shannon W, et al. Validation of clinical classification schemes for predicting stroke: results from the National Registry of Atrial Fibrillation. JAMA. 2001;285(22): 2864-70.

23. Lip GY, Andreotti F, Fauchier L, et al. Bleeding risk assessment and management in atrial fibrillation patients: a position document from the European Heart Rhythm Association, endorsed by the European Society of Cardiology Working Group on Thrombosis. Europace. 2011;13(5):723-46.

24. Pisters R, Lane DA, Nieuwlaat R, et al. A novel user-friendly score (HAS-BLED) to assess 1-year risk of major bleeding in patients with atrial fibrillation: the Euro Heart Survey. Chest. 2010;138(5):1093-100.

25. Freedman MD. Oral anticoagulants: pharmacodynamics, clinical indications and adverse effects. J Clin Pharmacol. 1992;32(3): 196-209.

26. Fuster V, Ryden LE, Cannom DS, et al. ACC/AHA/ESC 2006 guidelines for the management of patients with atrial fibrillation- executive summary: a report of the American College of Cardiology/American Heart Association Task Force on Practice Guidelines and the European Society of Cardiology Committee for Practice Guidelines (Writing Committee to Revise the 2001 Guidelines for the Management of Patients With Atrial Fibrillation). J Am Coll Cardiol. 2006;48(4):854-906.

27. Albers GW, Sherman DG, Gress DR, et al. Stroke prevention in nonvalvular atrial fibrillation: a review of prospective randomized trials. Ann Neurol. 1991;30(4):511-8.

28. Poulsen BK, Grove EL, Husted SE. New oral anticoagulants: a review of the literature with particular emphasis on patients with impaired renal function. Drugs. 2012;72(13):1739-41.

29. Budnitz DS, Lovegrove MC, Shehab N, Richards CL. Emergency hospitalizations for adverse drug events in older Americans. N Engl J Med. 2011;365:2002-12.

30. Wieloch M, Sjalander A, Frykman V, et al. Anticoagulation control in Sweden: reports of time in therapeutic range, major bleeding, and thrombo-embolic complications from the national quality registry AuriculA. Eur Heart J. 2011;32(18):2282-9.

31. van Walraven $\mathrm{C}$, Jennings A, Oake $\mathrm{N}$, et al. Effect of study setting on anticoagulation control: a systematic review and metaregression. Chest. 2006;129(5):1155-66.

32. Schwartz NE, Albers GW. Dabigatran challenges warfarin's superiority for stroke prevention in atrial fibrillation. Stroke. 2010;41(6):1307-9.

33. Eriksson BI, Quinlan DJ, Weitz JI. Comparative pharmacodynamics and pharmacokinetics of oral direct thrombin and factor xa inhibitors in development. Clin Pharmacokinet. 2009;48(1): $1-22$.

34. Bauer KA. Reversal of antithrombotic agents. Boehringer Ingelheim Limited. Pradaxar Mexican prescribing information [online]. http://www.medicamentos.com.mx. Accessed 6 June 2015.

35. Pollack CV, Reilly PA, Eikelboom J, et al. Idarucizumab for dabigatran reversal. N Engl J Med. 2015;373:511-20.

36. Siegal DM, Curnutte JT, Connolly SJ, et al. Andexanet alfa for the reversal of factor Xa inhibitor activity. N Engl J Med. 2015;373:2413-24.

37. Siegal DM, Curnutte JT, Connolly SJ, Genmin L, Wiens BL, Mathur VS, Castillo J, Bronson MD, Leeds JM, Mar FA, Gold A, Crowther MA. Andexanet alfa for the reversal of factor Xa inhibitor activity. N Engl J Med. 2015;373:2413-24.

38. Mo Y, Yam FK. Recent advances in the development of specific antidotes for target-specific oral anticoagulants. Pharmacotherapy. 2015;35(2):198-207.

39. Kaatz S, Mahan CE. Stroke prevention in patients with atrial fibrillation and renal dysfunction. Stroke. 2014;45(8):2497-505.

40. Stangier J. Clinical pharmacokinetics and pharmacodynamics of the oral direct thrombin Inhibitor dabigatran etexilate. Clin Pharmacokinet. 2008;47(5):285-95.

41. Boehringer Ingelheim Limited. Pradaxa $75 \mathrm{mg}$ hard capsules: summary of product characteristics [online]. http://www. medicines.org.uk/EMC/medicine/20759/SPC/Pradaxa $+75+\mathrm{mg}+$ hard+capsules/. Accessed 31 Jan 2015.

42. Boehringer Ingelheim Limited. Pradaxa $150 \mathrm{mg}$ hard capsules: summary of product 16 characteristics [online]. http://www. medicines.org.uk/EMC/medicine/24839/SPC/Pradaxa+150+mg+ hard+capsules/18. Accessed 31 Jan 2015.

43. COFEPRIS. Aprueba Cofepris el registro de nuevo anticoagulante [Mexican media release dated 27 June 2011]. http://www. medicinadigital.com/index.php/medicamentos/19122-apruebacofepris-el-23registro-de-nuevo-anticoagulante.html. Accessed 1 Feb 2015

44. Ezekowitz MD, Connolly S, Parekh A, et al. Rationale and design of RE-LY: randomized 25 evaluation of long-term anticoagulant therapy, warfarin, compared with dabigatran. Am Heart J. 2009;157(5):805-10 (10.e1-2). 
45. Connolly SJ, Ezekowitz MD, Yusuf S, et al. Dabigatran versus warfarin in patients with atrial fibrillation. [Erratum appears in $\mathrm{N}$ Engl J Med. 2010 Nov 4;363(19):1877]. N Engl J Med. 2009;361(12):1139-51.

46. Hohnloser SH, Oldgren J, Yang S, et al. Myocardial ischemic events in patients with atrial fibrillation treated with dabigatran or warfarin in the RE-LY (Randomized Evaluation of Long-Term Anticoagulation Therapy) trial. Circulation. 2012;125(5):669-76.

47. Hart RG, Diener H-C, Yang S, et al. Intracranial hemorrhage in atrial fibrillation patients during anticoagulation with warfarin or dabigatran: the RE-LY trial. Stroke. 2012;43(6):1511-7.

48. Wallentin L, Yusuf S, Ezekowitz MD, et al. Efficacy and safety of dabigatran compared with warfarin at different levels of international normalised ratio control for stroke prevention in atrial fibrillation: an analysis of the RE-LY trial. Lancet. 2010;376(9745):975-83.

49. Ezekowitz MD, Wallentin L, Connolly SJ, et al. Dabigatran and warfarin in vitamin $\mathrm{K}$ antagonist-naive and -experienced cohorts with atrial fibrillation. Circulation. 2010;122(22):2246-53.

50. Janssen Pharmaceuticals. Xarelto Prescribing Information [online]. http://www.xareltohcp.com/sites/default/files/pdf/xarelto_0. pdf\#zoom=100. Accessed 31 Jan 2015.

51. Bayer. Xarelto Mexican prescribing information [online]. http:// www.medicamentos.com.mx. Accessed 6 June 2015.

52. Hoffman M, Monroe DM. Coagulation 2006: a modern view of hemostasis. Hematol Oncol Clin N Am. 2007;21(1):1-11.

53. Mann KG, Brummel K, Butenas S. What is all that thrombin for? J Thromb Haemost. 2003;1(7):1504-14.

54. Spyropoulos AC. Investigational treatments of venous thromboembolism. Expert Opin Investig Drugs. 2007;16(4):431-40.

55. Patel MR, Mahaffey KW, Garg J, et al. Rivaroxaban versus warfarin in nonvalvular atrial fibrillation. $\mathrm{N}$ Engl $\mathrm{J}$ Med. 2011;365(10):883-91.

56. US Food and Drug Administration. FDA approves Eliquis to reduce the risk of stroke, blood clots in patients with non-valvular atrial fibrillation [Media release dated 28 December 7 2012]. http://www.fda.gov/NewsEvents/Newsroom/PressAnnouncements/ ucm333634.htm9. Accessed 12 Apr 2015.

57. Pfizer. Eliquis (apixaban) approved in Europe for prevention of stroke and systemic 12 embolism in patients with nonvalvular atrial fibrillation [Media release dated November 13 2012]. http:// press.pfizer.com/press-release/eliquisapixaban-approved-europeprevention-stroke-and-systemic-embolism-patients-nonva. Accessed 12 Apr 2015.

58. Pfizer. Eliquis (apixaban) $2.5 \mathrm{mg}$ and $5 \mathrm{mg}$ film-coated tablets 17 prescribing information [online]. http://www.pfizer.ca/sites/g/ files/g10017036/f/201505/Marketed_ELIQUIS_178226_PM_ 200215.pdf. Accessed 30 Sept 2015.

59. Granger CB, Alexander JH, McMurray JJV, et al. Apixaban versus warfarin in patients with atrial fibrillation. $\mathrm{N}$ Engl $\mathrm{J}$ Med. 2011;365(11):981-92.

60. Connolly SJ, Eikelboom J, Joyner C, et al. Apixaban in patients with atrial fibrillation. N Engl J Med. 2011;364(9):806-17.

61. Lopes RD, Al-Khatib SM, Wallentin L, et al. Efficacy and safety of apixaban compared with warfarin according to patient risk of stroke and of bleeding in atrial fibrillation: a secondary analysis of a randomised controlled trial. Lancet. 2012;380(9855): 1749-58.

62. Lawrence J, Pogue J, Synhorst D, et al. Apixaban versus aspirin in patients with atrial fibrillation and previous stroke or transient ischaemic attack: a predefined subgroup analysis from AVERROES, a randomised trial. Lancet Neurol. 2012;11(3):225-31.

63. Edoxaban (Savaysa).The fourth new oral anticoagulant. Med Lett Drugs Ther. 2015;57(1465):43-5.

64. Giugliano RP, Ruff CT, Braunwald E, Murphy SA, Wiviott SD, Halperin JL, Waldo AL, Ezekowitz MD, Weitz JI, Špinar J,
Ruzyllo W, Ruda M, Koretsune Y, Betcher J, Shi M, Grip LT, Patel SP, Patel I, Hanyok JJ, Mercuri M, Antman EM, ENGAGE AF-TIMI 48 Investigators. Edoxaban versus warfarin in patients with atrial fibrillation. N Engl J Med. 2013;369:2093-104.

65. Sherwood MW, Douketis JD, Patel MR, et al. Outcomes of temporary interruption of rivaroxaban compared with warfarin in patients with nonvalvular atrial fibrillation: results from the rivaroxaban once daily, oral, direct factor Xa inhibition compared with vitamin $\mathrm{K}$ antagonism for prevention of stroke and embolism trial in atrial fibrillation (ROCKET AF). Circulation. 2014;129:1850.

66. Capodanno D, Capranzano P, Giacchi G, et al. Novel oral anticoagulants versus warfarin in non-valvular atrial fibrillation: a meta-analysis of 50,578 patients. Int J Cardiol. 2013;167: $1237-41$.

67. Miller CS, Grandi SM, Shimony A, et al. Meta-analysis of efficacy and safety of new oral anticoagulants (dabigatran, rivaroxaban, apixaban) versus warfarin in patients with atrial fibrillation. Am J Cardiol. 2012;110(3):453-60.

68. Lip GY, Larsen TB, Skjoth F, et al. Indirect comparisons of new oral anticoagulant drugs for efficacy and safety when used for stroke prevention in atrial fibrillation. J Am Coll Cardiol. 2012;60(8):738-46.

69. Testa L, Agnifili M, Latini RA, et al. Adjusted indirect comparison of new oral anticoagulants for stroke prevention in atrial fibrillation. QJM. 2012;105(10):949-57.

70. Mantha S, Ansell J. An indirect comparison of dabigatran, rivaroxaban and apixaban for atrial fibrillation. Thromb Haemost. 2012;108(3):476-84.

71. Baker WL, Phung O. Do differences exist between oral anticoagulants in patients with nonvalvular atrial fibrillation? An adjusted indirect comparison meta-analysis free. J Am Coll Cardiol. 2012;59(13s1):E597. doi:10.1016/S0735-1097(12)60598-1.

72. Lip GH, Lane DA. Stroke prevention in atrial fibrillation: a systematic review. JAMA. 2015;313(19):1950-62.

73. Hemphill JC, Greenberg SM, et al. Guidelines for the management of spontaneous intracerebral hemorrhage: a guideline for healthcare professionals from the American Heart Association/ American Stroke Association. Stroke. 2015;46:2032-60.

74. Healey JS, Eikelboom J, Douketis J, et al. Periprocedural bleeding and thromboembolic events with dabigatran compared with warfarin: results from the Randomized Evaluation of LongTerm Anticoagulation Therapy (RE-LY) randomized trial. Circulation. 2012;126:343.

75. Garcia D, Alexander JH, Wallentin L, et al. Management and clinical outcomes in patients treated with apixaban vs warfarin undergoing procedures. Blood. 2014;124:3692.

76. Gobierno Federal Estados Unidos Mexicanos. Guía de práctica clínica: prevención secundaria en el tratamiento con anticoagulante oral: warfarina en adultos en el preimer nivel de atención médica. Evidencias y Recomendaciones: catalogo maestro de guías de práctica clínica: IMSS-101-08. http://www.cenetec. salud.gob.mx/descargas/gpc/CatalogoMaestro/101_GPC_Txantic Warfari1na/ANTICOAGULANTE_EVR_CENETEC.pdf. Accessed 12 Apr 2015.

77. Gobierno Federal Estados Unidos Mexicanos. Guía de práctica clínica (GPC): 3 actualización 2011. Diagnóstico y tratamiento de la fibrilación auricular. Evidencias y Recomendaciones: catalogo maestro de guías de práctica clínica: SS-014-08. http://www. cenetec.salud.gob.mx/descargas/gpc/CatalogoMaestro/014_GPC_ FibrilacionAuricular/SS_014_08_EyR.pdf. Accessed 12 Apr 2015.

78. Verma A, Cairns JA, Mitchell B, et al. 2014 Focused update of the Canadian Cardiovascular Society Guidelines for the management of atrial fibrillation. Can J Cardiol. 2014;30(10): 1114-30. 